and the non-diabetic rats the heaviest. Diet appeared to have no effect on BMT, although diabetic status (second factor) had a highly significant effect. The values for BMT were very similar in all the diabetic groups and much higher than those for the non-diabetic rats. For BMT corrected for body weight the main effects of both factors were significant. The values were very similar in the two non-diabetic groups $(0.52$ and $0.53 \mathrm{~nm} / \mathrm{g})$ but increased in group $4(0.67 \mathrm{~nm} / \mathrm{g})$. Untreated diabetics had greatly increased values $(0.99 \mathrm{~nm} / \mathrm{g})$, while the thickening was almost as severe $(0.90 \mathrm{~nm} / \mathrm{g})$ in the poorly controlled diabetics on insulin or low carbohydrate diet alone.

\section{Discussion}

Insulin, in addition to its well-recognised effect on glucose homeostasis, is essential to body growth and development. ${ }^{6}$ In other words, normal growth and effective blood glucose control go hand in hand. This is borne out by our results, which showed that in streptozocin-diabetic rats treated with insulin plus a low carbohydrate diet (group 4) not only was glucose homeostasis (MPG) closest to normal but the body weight also reached control values. When BMT was corrected for body weight diabetic rats in group 4 had less BMT than other less wellcontrolled diabetic animals. It might seem paradoxical that hyperglycaemia should be associated on the one hand with poor body growth and on the other hand with excessive basement membrane thickening. There is, however, good experimental evidence to show how glucose is accumulated in the glycoprotein matrix of basement membrane in hyperglycaemic states. ${ }^{3}$ ? Although renal failure in diabetics is terminally associated with glomerulosclerosis complicated by fibrin deposition, hyalinisation, and often hypertensive changes, ${ }^{4}$ basement membrane thickening is the first step in the process.

The strong relation between basement membrane thickening and hyperglycaemia found in this study suggests strongly that blood glucose control rather than insulin administration determines BMT. Although we have dealt here with the relation between good diabetic control and morphological changes, we have also found in the same group of animals that plasma glucose concentration correlates inversely with motor nerve conduction velocity. ${ }^{8}$ These findings should offer encouragement not only to those who treat diabetic patients with the aim of maintaining good blood glucose control but also to those who search for improved methods of achieving this aim. ${ }^{9} 10$

We are grateful to Miss $\mathrm{V}$ Wright and $\mathrm{Mr} \mathrm{S}$ Terras for excellent technical help. The streptozocin was donated by Dr W E Dulin, Upjohn Corporation, Kalamazoo, Michigan, and the monocomponent insulin by Dr J Schlichtkrull, Novo Research Laboratories, Copenhagen. Financial support was provided by a Medical Research Council Project Grant, St Thomas's Hospital Research (Endowments) Committee, and the Higher Medicine Fund of the Greater Glasgow Health Board.

\section{References}

${ }^{1}$ Crofford, O B, Report of the National Commission on Diabetes to the Congress of the United States. United States Department of Health, Education and Welfare Publication No (NIH) 67-1018. Washington, DC, Government Printing Office, 1975.

${ }^{2}$ Department of Health and Social Security, Incidence and Causes of Blindness in England and Wales, 1963-1968 by A Sorsby, p 33. London, HMSO, 1972.

${ }^{3}$ Spiro, R G, Diabetologia, 1976, 12, 1 .

Cameron, J S, Ireland, J T, and Watkins, P J, Complications of Diabetes, ed $\mathrm{H}$ Keen and J Jarrett, p 99. London, Arnold, 1975.

${ }^{5}$ Ireland, J T, Patnaik, B K, and Duncan, L J P, Diabetes, 1967, 16, 628.

${ }^{6}$ Sönksen, P H, Proceedings of the Royal Society of Medicine, 1975, 68, 707.

Beisswenger, P H, and Spiro, R G, Diabetes, 1973, 22, 180.

${ }^{8}$ Fox, C, Lowy, C, and Sönksen, P H, Clinical Science and Molecular Medicine, 1977, 52, 24P.

9 Lancet, 1975, 2, 909.

"Cahill, G F, Etzwiler, D D, and Freinkel, N, New England fournal of Medicine, 1976, 294, 1004.

(Accepted 15 fuly 1977)

\title{
SIDE EFFECTS OF DRUGS
}

\section{Hypertensive crisis in a patient given Sinemet, metoclopramide, and amitriptyline}

Many patients with Parkinson's disease are depressed. The patient described here, who was on amitriptyline, suffered a hypertensive crisis shortly after being given Sinemet (levodopa and carbidopa) and metoclopramide.

\section{Case report}

A 60-year-old housewife had had symptoms of Parkinson's disease for six months. An attempt to treat her as an outpatient with Sinemet had been abandoned because it produced intolerable nausea. She was therefore brought into hospital for control of her symptoms. On admission she was taking amitriptyline $20 \mathrm{mg}$ at night, together with digoxin $0.125 \mathrm{mg}$ and cyclopenthiazide $0.5 \mathrm{mg}$ in the morning, which her general practitioner had given her since he had found her blood pressure to be $190 / 100 \mathrm{~mm} \mathrm{Hg}$ two months earlier. On admission her blood pressure was $190 / 110 \mathrm{~mm} \mathrm{Hg}$.

She was started on Sinemet 110 (levodopa $100 \mathrm{mg}$, carbidopa $10 \mathrm{mg}$ ) half a tablet and metoclopramide $10 \mathrm{mg}$, each given thrice daily. Twenty-four hours later her blood pressure began to rise, and over 10 hours it rose from $170 / 110 \mathrm{~mm} \mathrm{Hg}$ to $270 / 140 \mathrm{~mm} \mathrm{Hg}$. She was flushed and complained of headache and breathlessness. Her pulse rate was 80 beats/minute and there were no signs of cardiac failure. After intravenous diazoxide $300 \mathrm{mg}$ her blood pressure fell, over two hours, to $150 / 80 \mathrm{~mm} \mathrm{Hg}$ and symptoms disappeared. A relationship between this hypertensive episode and the patient's treatment was not immediately suspected and her treatment was not changed. Nine hours after the first bolus of diazoxide her blood pressure again began to rise, over 12 hours, from $160 / 90 \mathrm{~mm} \mathrm{Hg}$ to $240 / 140 \mathrm{~mm} \mathrm{Hg}$; her pulse rate rose over the same interval from 80 to 140 beats/minute (sinus rhythm) and she again became flushed and breathless. After diazoxide $150 \mathrm{mg}$ intravenously, the blood pressure fell to $160 / 90 \mathrm{~mm} \mathrm{Hg}$ and there was again symptomatic improvement; her pulse rate fell to 80 beats/minute. Sinemet, metoclopramide, and amitriptyline were now discontinued. Her blood pressure remained at about $160 / 90 \mathrm{~mm} \mathrm{Hg}$ and pulse rate at about 80 beats/minute throughout the rest of her admission. Three 24-hour urinary vanillylmandelic acid estimations gave normal values.

On a subsequent admission three weeks later bromocryptine (in a final total dose of $25 \mathrm{mg}$ daily) and orphenadrine ( $50 \mathrm{mg}$ three times daily) were successfully and uneventfully used to control her Parkinsonism.

\section{Comment}

Its temporal relationship to the agents administered suggests that this hypertensive crisis was probably drug-related. An attempt to investigate it further by challenging the patient with the drugs singly or in combination was thought to be unjustifiable.

Although levodopa may rarely produce hypertensive responses, ${ }^{1}$ acute increases in blood pressure after administration of either Sinemet or carbidopa alone ${ }^{1}$ have not been reported. Metoclopramide blocks dopamine receptors but does not antagonise the common hypotensive effect of levodopa. ${ }^{2}$ On the other hand, metoclopramide has been shown to produce hypertensive crises in patients with phaeochromocytoma, ${ }^{3}$ possibly by causing catecholamine release from the tumour. Limited investigations for phaeochromocytoma in this patient were, however, negative. Amitriptyline given by itself has not been reported to cause pressor responses and this patient had been taking it for several weeks before the crisis occurred. Amitriptyline prevents 
active cellular reuptake of released noradrenaline, ${ }^{4}$ and this probably contributes to its antagonism of antihypertensive agents and to its hypertensive interaction with monoamine oxidase inhibitors. Although tricyclic antidepressants may theoretically potentiate the pressor effect of noradrenaline derived from levodopa, the combination of amitriptyline and levodopa is apparently $\mathrm{safe}^{4}{ }^{4}$ and there are no reports of hypertensive crises in patients on Sinemet and amitriptyline. Furthermore, hypertensive responses to other combinations of Sinemet, amitriptyline, and metoclopramide have not previously been described.

These three agents are not uncommonly used together to treat patients with Parkinson's disease, and prescribers should be aware of the possibility of a potentially dangerous reaction to such treatment.

I thank Dr P K Harvey and Dr G M Stern for their advice.

${ }^{1}$ Chase, T N, and Watanabe, A M, Neurology (Minneapolis), 1972, 22,

384.
2 Parkes, J D, Debono, A G, and Marsden, C D, fournal of Neurology, Neurosurgery and Psychiatry, 1976, 39, 1101.

${ }^{3}$ Agabiti-Rosei, E, Alicandri, C L, and Corea, L, Lancet, 1977, 1, 600.

${ }^{4}$ Bianchine, J R, and Sunyapridakul, L, Drugs, 1973, 6, 364.

(Accepted 29 fune 1977)

Department of Neurology, Whittington Hospital, London N19

D S RAMPTON, DPHIL, MRCP, medical registrar

\section{Ventricular arrhythmias caused by prenylamine}

Prenylamine is a drug widely used to treat angina pectoris. We describe here two patients with prolongation of the $\mathrm{Q}-\mathrm{T}$ interval complicated by serious ventricular arrhythmias and syncope due to prenylamine.

\section{Case 1}

A 78-year-old woman was admitted to hospital after collapsing at home. She had had palpitations and dizzy spells for a few weeks. An electrocardiogram taken during a visit to the casualty department the previous day after a faint had shown sinus rhythm at 52 beats/min and a Q-T interval of $0.62 \mathrm{~s}$, but the significance of this was not recognised and the patient was sent home.

She had mild diabetes mellitus controlled by diet, and exertional angina pectoris, and she had had a left total hip replacement for osteoarthritis three years earlier. She was taking prenylamine $180 \mathrm{mg}$ daily, as well as Feospan (dried ferrous sulphate), diazepam, allopurinol, and oxyphenbutazone.

During transfer to hospital in a coronary ambulance the monitoring oscilloscope showed only sinus rhythm with occasional ventricular extrasystoles. In hospital she had an episode of ventricular tachycardia, sinus rhythm being restored by DC countershock. The patient was then given intravenous lignocaine but then had 87 documented episodes of ventricular tachycardia over the next 90 minutes, many of them displaying the "torsade de pointes" phenomenon (fig 1). A full electrocardiogram showed sinus bradycardia, right bundle-branch block, giant bizarre $T$ waves, prominent $U$ waves, a much prolonged $\mathrm{Q}-\mathrm{T}$ interval of at least $0.8 \mathrm{~s}$, and coupled ventricular extrasystoles (fig 2).

As soon as the nature of the emergency was understood right atrial pacing was started at a rate of 120 beats/min, which immediately suppressed the arrhythmia. Pacing at fast rates was completely effective over 72 hours until spontaneous improvement occurred. Investigations showed: serum potassium $3.1 \mathrm{mmol}(\mathrm{mEq}) / 1$, normal serum calcium; and no enzyme evidence of myocardial infarction. After withdrawal of prenylamine serial electrocardiograms showed that the Q-T interval gradually returned to normal; four weeks after admission it was $0.40 \mathrm{~s}$ (fig 3).

\section{Case 2}

A 62-year-old woman presented with a history of four blackouts in the preceding four months. These blackouts lasted a few minutes and made her feel breathless for a short time afterwards but were not associated with palpitations. For the previous 20 months she had been taking Navidrex $\mathbf{K}$ (cyclopenthiazide $250 \mu \mathrm{g}$ and potassium chloride $600 \mathrm{mg}$ ), propranolol, and prenylamine $180 \mathrm{mg}$ daily to help control her angina and hypertension.

The pulse was regular at 48 beats/min and the blood pressure was $250 / 100$
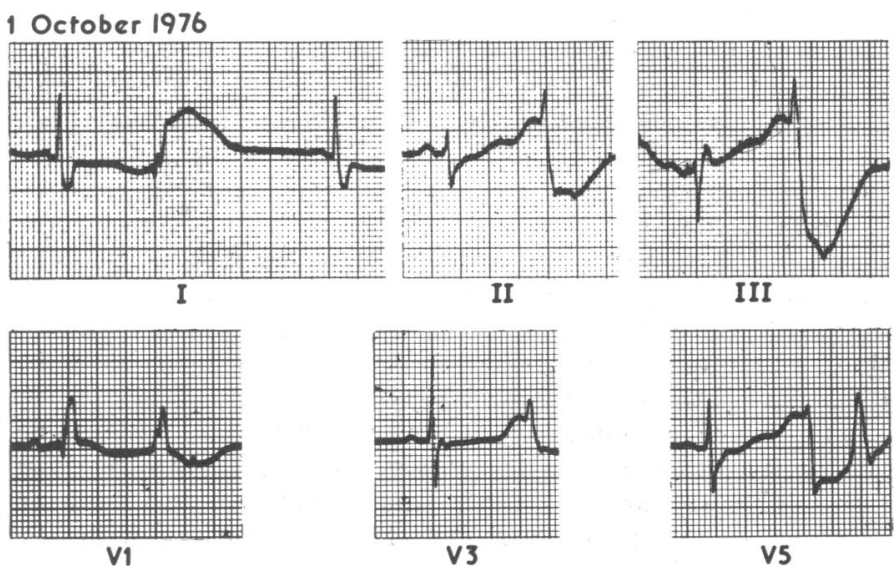

V5

FIG 2-Case 1. ECG showing giant bizarre T-U segments and coupled ventricular extrasystoles.

V5

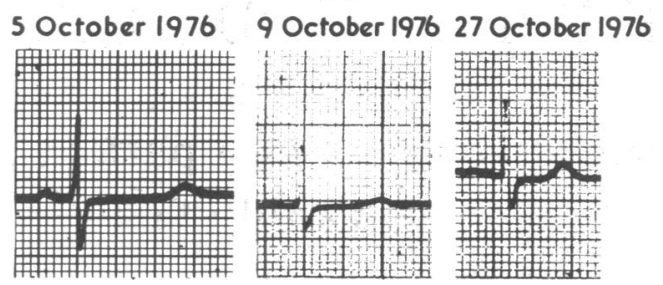

FIG 3-Case 1. ECG showing improvement of Q-T prolongation over three weeks after withdrawal of prenylamine.

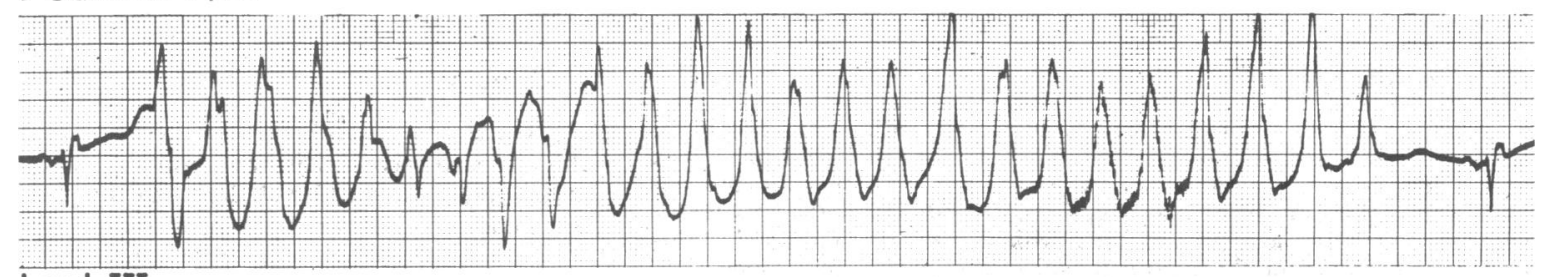

Lead III

FIG 1 -Case 1. One of 87 documented (magnetic tape) episodes of ventricular tachycardia that occurred over 90 minutes. This example shows waveforms characteristic of torsade de pointes phenomenon.

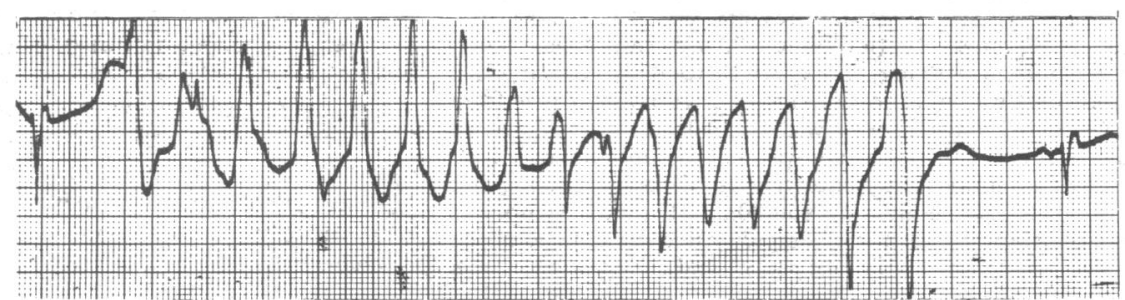

